Article

\title{
High Potency of Melaleuca alternifolia Essential Oil against Multi-Drug Resistant Gram-Negative Bacteria and Methicillin-Resistant Staphylococcus aureus
}

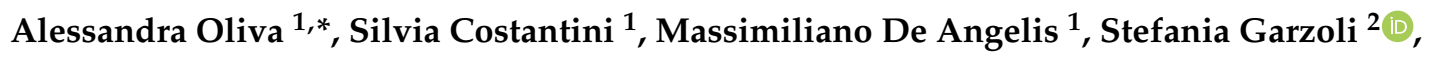 \\ Mijat Božović ${ }^{3}$ (-), Maria Teresa Mascellino ${ }^{1}$, Vincenzo Vullo ${ }^{1}$ and Rino Ragno ${ }^{4,5, *(1)}$ \\ 1 Department of Public Health and Infectious Diseases, Sapienza University of Rome, Viale del Policlinico 155, \\ 00161 Rome, Italy; silviacostantini89@gmail.com (S.C.); massimiliano.deangelis@uniroma1.it (M.D.A.); \\ mariateresa.mascellino@uniroma1.it (M.T.M.); vincenzo.vullo@uniroma1.it (V.V.) \\ 2 Department of Drug Chemistry and Technology, Sapienza University, P.le Aldo Moro 5, 00185 Rome, Italy; \\ stefania.garzoli@uniroma1.it \\ 3 Faculty of Natural Sciences and Mathematics, University of Montenegro, Džordža Vašingtona bb, \\ 81000 Podgorica, Montenegro; mijatboz@gmail.com \\ 4 Rome Center for Molecular Design, Department of Drug Chemistry and Technology, Sapienza University, \\ P.le Aldo Moro 5, 00185 Rome, Italy \\ 5 Alchemical Dynamics s.r.l., 00125 Rome, Italy \\ * Correspondence: alessandra.oliva@uniroma1.it (A.O.); rino.ragno@uniroma1.it (R.R.); \\ Tel.: +39-(0)649-970-880 or +39-3291-264-636 (A.O.); +39-(0)649-913-937 (R.R.)
}

Received: 8 August 2018; Accepted: 7 October 2018; Published: 9 October 2018

check for updates

\begin{abstract}
Purpose: Herein, an extended investigation of Tea tree oil (TTO) against a number of multi-drug resistant (MDR) microorganisms in liquid and vapor phases is reported. Methods: The activity of TTO was tested against methicillin-sensitive Staphylococcus aureus (MSSA), Escherichia coli, and clinical strains of methicillin-resistant S. aureus (MRSA), extended-spectrum beta lactamases producer carbapenem-sensitive Klebsiella pneumoniae (ESBL-CS-Kp), carbapenem-resistant K. pneumoniae (CR-Kp), Acinetobacter baumannii (CR-Ab), and Pseudomonas aeruginosa (CR-Pa). Minimal inhibitory/bactericidal concentrations (MIC/MBCs) and synergistic activity between TTO and different antimicrobials were determined. In the vapor assay (VP), TTO-impregnated discs were placed on the lid of a petri dish and incubated for $24 \mathrm{~h}$ at $37^{\circ} \mathrm{C}$. Results: TTO showed a potent bactericidal activity against all the tested microorganisms. TTO in combination with each reference antimicrobial showed a high level of synergism at sub-inhibitory concentrations, particularly with oxacillin (OXA) against MRSA. The VP assay showed high activity of TTO against CR-Ab. Conclusion: Evaluation of in-vitro activity clearly indicated TTO as a potential effective antimicrobial treatment either alone or in association with known drugs against MDR. Therefore, TTO could represent the basis for a possible role in non-conventional regimens against S. aureus and Gram-negative MDR. TTO in VP might represent a promising option for local therapy of pneumonia caused by CR-Ab.
\end{abstract}

Keywords: multi-drug resistant bacteria; essential oils; Melaleuca alternifolia; methicillin-resistant Staphylococcus aureus; carbapenem-resistant microorganisms

\section{Introduction}

The emergence of multidrug-resistant (MDR) microorganisms represents a global challenge worldwide, since therapeutic options are limited, resulting in thousands of deaths [1]. Furthermore, there is a paucity of novel and effective antimicrobial agents in the pipeline, especially against 
carbapenem-resistant (CR) Acinetobacter baumannii and CR Enterobacteriaceae carrying enzymes other than class A carbapenemases [2].

Essential oils (EOs) are volatile, natural, fragrant liquids that can be extracted from different parts of the plants (especially leaves and flowers) presenting anti-inflammatory, antiviral, and antibacterial properties [3]. Given their antimicrobial activity broad-spectrum, together with the possibility of restoring antibiotic susceptibility [4,5], several efforts have been made to consider the use of EOs for the treatment of a wide range of infections, including those caused by MDR microorganisms [6]. EOs' activity is commonly ascribed to the perturbation of cell membrane structural integrity, leading bacterial cell to death [7] and their potency varies with the type of microorganisms, Gram-positive bacteria being more susceptible than Gram-negatives [8-11].

Tea tree oil (TTO) is produced by steam distillation of leaves and terminal branches of Melaleuca alternifolia and is currently used in traditional medicine as a topical antiseptic and anti-inflammatory agent and widely formulated into many cosmetic and personal care products [12]. TTO is mainly known for its antibacterial properties [13], exerted by the inhibition of bacterial respiration and the disruption of the permeability barrier of microbial membrane structures, as well as by the induction of a leakage of potassium ions, both in Gram-positive and Gram-negative bacteria [14]; in addition, it has been widely investigated in synergy with conventional antimicrobials, such as vancomycin [15] and aminoglycosides for S. aureus and E. coli [16] and, recently, combined with different nanoparticles [17]. However, little is known with regard to the activity of TTO against MDR and pan-drug resistant (PDR) Gram-negative strains both in liquid and VP as well as the potential interaction (i.e., restoring antibiotic sensitivity) between beta-lactams and TTO towards MRSA.

Based on the above considerations and continuing the investigations on EOs as effective antimicrobial agents [10,18-23], the main aim of this report was to evaluate the in-vitro activity of a chemically characterized commercial TTO, alone and in combination with different antimicrobials, against methicillin-susceptible Staphylococus aureus (MSSA), methicillin-resistant Staphylococus aureus (MRSA), Escherichia coli and MDR Gram-negative bacteria including extended-spectrum beta lactamases (ESBLs) producer carbapenem-sensitive Klebsiella pneumoniae (ESBL-CS-Kp), ESBL and carbapenem-resistant K. pneumoniae (CR-Kp), carbapenem-resistant Acinetobacter baumannii (CR-Ab) and carbapenem-resistant Pseudomonas aeruginosa (CR-Pa). In addition, the antibacterial effectiveness of TTO in the VP against the abovementioned microorganisms was investigated.

\section{Results}

\subsection{TTO Chemical Characterization}

Chemical TTO characterization was performed throughout gas chromatographic/mass spectrometric (GC/MS) analysis both in the liquid and vapor phase (VP).

Among the several chemical components contained in the TTO sample (Table 1), terpinen 4-ol, eucalyptol, $\alpha$-pinene, and $\gamma$-terpinene were found to be the most abundant by the classical GC/MS analysis performed on the liquid EO (35.4\%, 15.2\%, 12.4\%, 9.8\%, respectively). A different scenario was instead observed by performing the EO VP analysis through headspace technique. A direct comparison of the two analyses indicated a marked increase in the percentage of $\alpha$-pinene $(22.5 \%)$ and almost $20 \%$ reduction in terpinen $4-\mathrm{ol}(28.7 \%)$ in the VP. 
Table 1. Chemical composition (\%) of TTO.

\begin{tabular}{|c|c|c|c|c|c|}
\hline$\#^{1}$ & Component $^{2}$ & LRI $^{3}$ & $\mathrm{LRI}_{\text {lit }} 4$ & $\mathrm{~A} 1 \%^{5}$ & $A 2 \%{ }^{6}$ \\
\hline 1 & $\alpha$-pinene & 1040 & 1039 & 12.4 & 22.5 \\
\hline 2 & $\beta$-pinene & 1131 & 1124 & 1.8 & 2.4 \\
\hline 3 & 1,4-cineole & 1192 & 1192 & 0.5 & - \\
\hline 4 & $\alpha$-terpinene & 1197 & 1195 & 2.8 & 2.9 \\
\hline 5 & d-limonene & 1216 & 1219 & 2.3 & 2.8 \\
\hline 6 & eucalyptol & 1231 & 1230 & 15.2 & 16.5 \\
\hline 7 & $\gamma$-terpinene & 1266 & 1265 & 9.8 & 10.7 \\
\hline 8 & o-cymene & 1291 & 1287 & 6.3 & 8.5 \\
\hline 9 & terpinolene & 1306 & 1299 & 1.6 & 1.6 \\
\hline 10 & aromadendrene & 1600 & 1603 & 1.9 & - \\
\hline 11 & terpinen-4-ol & 1631 & 1633 & 35.4 & 28.7 \\
\hline 12 & $\alpha$-terpineol & 1718 & 1724 & 8.1 & 3.4 \\
\hline 13 & ledene & 1715 & 1707 & 1.1 & - \\
\hline 14 & globulol & 2110 & 2104 & 0.8 & - \\
\hline Total & & & & 100 & 100 \\
\hline
\end{tabular}

1: compound identification number; ${ }^{2}$ : components are listed according to their elution order on a polar column. ${ }^{3}$ : Linear Retention indices measured on a polar column; ${ }^{4}$ : Linear Retention indices from literature; ${ }^{5}$ : Area by standard GC-MS (\%); ${ }^{6}$ : Area by Head Space GC-MS (\%). Only chemical components with percentages greater than $0.1 \%$ were included.

\subsection{Antimicrobial Susceptibility}

TTO minimal inhibitory / bactericidal concentrations (MIC/MBCs, respectively) were evaluated against a list of standard and clinical isolate strains of important microorganisms such as MSSA, E. coli, MRSA, ESBL-CS-Kp, CR-Ab, and CR-Pa. AMK, CFZ, MEM, OXA, COL, RIF and VAN were used as references drugs (Table 2). As expected, CR strains exhibited high MEM MIC/MBC values whereas both MSSA and MRSA showed sensitivity to VAN and RIF.

TTO showed a potent bactericidal activity (expressed in $v / v$ percentage) against all the tested Gram-negative microorganisms, with MIC/MBCs $0.25 \% / 0.25 \%$ for CR-Ab, CR-Kp and E. coli, $1 \% / 1 \%$ for CR-Pa, $0.5 \% / 0.5 \%$ for ESBL-CS-Kp. With regard to MSSA and MRSA, MIC/MBCs were $1 \% / 2 \%$ and $0.5 \% / 2 \%$, respectively. For all the tested microorganisms, the $\mathrm{MBC}$ resulted in absence of bacterial growth after $24 \mathrm{~h}$ of incubation.

\subsection{Synergistic Activity}

TTO in combination with each reference antimicrobial showed a high level of synergism at sub-inhibitory concentrations, especially with CFZ/OXA/AMK against both MSSA and MRSA and with MEM/AMK/COL against all Gram-negative microorganisms (Table 3).

Notably, TTO at sub-inhibitory concentrations lowered OXA and CFZ MICs for MRSA from 64 to $2 \mu \mathrm{g} / \mathrm{mL}$ and from 32 to $1 \mu \mathrm{g} / \mathrm{mL}$, respectively. 
Table 2. Antibacterial activity of TTO and different antimicrobials against MSSA, MRSA, Escherichia coli, ESBL-CS-Kp, ESBL-CR-Kp, CR-Ab, and CR-Pa.

\begin{tabular}{|c|c|c|c|c|c|c|c|c|c|c|c|c|c|c|c|c|}
\hline \multirow{3}{*}{ Strains } & \multicolumn{2}{|c|}{ TTO $^{1}$} & \multicolumn{2}{|c|}{ AMK $^{2}$} & \multicolumn{2}{|c|}{ OXA $^{3}$} & \multicolumn{2}{|c|}{$\mathrm{CFZ}^{4}$} & \multicolumn{2}{|c|}{ VAN $^{5}$} & \multicolumn{2}{|c|}{ RIF $^{6}$} & \multicolumn{2}{|c|}{ MEM $^{7}$} & \multicolumn{2}{|c|}{$\mathrm{COL}^{8}$} \\
\hline & $\operatorname{MIC}^{9}$ & $\underset{10}{\operatorname{MBC}}$ & MIC & MBC & MIC & МBC & MIC & MBC & MIC & MBC & MIC & MBC & MIC & MBC & MIC & MBC \\
\hline & \multicolumn{2}{|c|}{$\% v / v$} & \multicolumn{2}{|c|}{$\mu \mathrm{g} / \mathrm{mL}$} & \multicolumn{2}{|c|}{$\mu \mathrm{g} / \mathrm{mL}$} & \multicolumn{2}{|c|}{$\mu \mathrm{g} / \mathrm{mL}$} & \multicolumn{2}{|c|}{$\mu \mathrm{g} / \mathrm{mL}$} & \multicolumn{2}{|c|}{$\mu \mathrm{g} / \mathrm{mL}$} & \multicolumn{2}{|c|}{$\mu \mathrm{g} / \mathrm{mL}$} & \multicolumn{2}{|c|}{$\mu \mathrm{g} / \mathrm{mL}$} \\
\hline MSSA $^{11}$ & 1 & 2 & 4 & 8 & 0.25 & 0.50 & 0.50 & 0.50 & 0.50 & 1 & 0.007 & 0.007 & & & & \\
\hline MRSA $^{12}$ & 0.50 & 2 & 32 & 32 & 32 & 64 & 64 & 128 & 1 & 1 & 0.007 & 0.007 & & & & \\
\hline E. coli $^{13}$ & 0.25 & 0.25 & 4 & 4 & & & & & & & & & 0.060 & 0.060 & 0.50 & 0.50 \\
\hline ESBL-CS-Kp 14,15,16 & 0.50 & 0.50 & 0.50 & 0.50 & & & & & & & & & 0.125 & 0.250 & 256 & 256 \\
\hline ESBL-CR 17 & 0.25 & 0.25 & 64 & 64 & & & & & & & & & 256 & 512 & 128 & 128 \\
\hline CR-Ab 18 & 0.25 & 0.25 & 8 & 16 & & & & & & & & & 64 & 128 & 0.25 & 0.25 \\
\hline CR-Pa 19 & 1 & 1 & 8 & 8 & & & & & & & & & 8 & 16 & 1 & 2 \\
\hline
\end{tabular}

${ }^{1}$ : Tea Tree Oili; ${ }^{2}$ : amikacin; ${ }^{3}$ : oxacillin; ${ }^{4}$ : cefazolin; ${ }^{5}$ : vancomycin; ${ }^{6:}$ rifampin $;{ }^{7}:$ meropenem; ${ }^{8}:$ colistin. ${ }^{9}:$ Minimal Inhibitory Concentration; ${ }^{10}:$ Minimal Bactericidal Concentration;

${ }^{16}$ : Kp; ${ }^{17}$ : Carbapenem-Resistant; ${ }^{18}$ : Acinetobacter baumannii; ${ }^{19}$ : Pseudomonas aeruginosa; ${ }^{20}$ : Not Active.

Table 3. Qualitative assessment of synergistic activity by FICI * values of TTO combined with different antimicrobials against MSSA, MRSA; Escherichia coli, ESBL-CS-Kp, ESBL-CR-Kp, CR-Ab, and CR-Pa.

\begin{tabular}{|c|c|c|c|c|c|c|c|}
\hline Strains & $\mathrm{TTO}^{1}+\mathrm{AMK}^{2}$ & $\mathrm{TTO}+\mathrm{OXA}^{3}$ & $\mathrm{TTO}+\mathrm{CFZ}^{4}$ & TTO + VAN ${ }^{5}$ & TTO + RIF ${ }^{6}$ & $\mathrm{TTO}^{2} \mathrm{MEM}^{7}$ & $\mathrm{TTO}+\mathrm{COL}^{\varepsilon}$ \\
\hline MSSA $^{9}$ & 0.25 & 0.32 & 0.25 & $>0.5$ & 0.32 & - & - \\
\hline MRSA 10 & 0.20 & 0.32 & 0.32 & $>0.5$ & 0.32 & - & - \\
\hline E. coli ${ }^{11}$ & 0.25 & $\mathrm{NA}^{18}$ & NA & NA & NA & $>0.50$ & 0.13 \\
\hline ESBL-CS-Kp $12,13,14$ & $>0.50$ & NA & NA & NA & NA & 0.50 & 0.32 \\
\hline ESBL-CR-Kp 15 & 0.50 & NA & NA & NA & NA & 0.32 & 0.32 \\
\hline CR-Ab ${ }^{16}$ & 0.32 & NA & NA & NA & NA & 0.32 & 0.21 \\
\hline $\mathrm{CR}-\mathrm{Pa} 17$ & 0.25 & NA & NA & NA & NA & 0.50 & 0.25 \\
\hline
\end{tabular}

*: FIC index; ${ }^{1}$ : Tea Tree Oil; ${ }^{2}$ : amikacin; ${ }^{3}$ : oxacillin; ${ }^{4}$ : cefazolin; ${ }^{5}$ : vancomycin; ${ }^{6}$ : rifampin; ${ }^{7}:$ meropenem; ${ }^{8}$ : colistin.; ${ }^{9}$ : Methicillin-susceptibility Staphylococcus aureus;

${ }^{10}$ : Methicillin-resistant Staphylococcus aureus; ${ }^{11}$ : Escherichia coli; ${ }^{12}$ : Extended Spectrum Beta-Lactamases; ${ }^{13}$ : Carbapenem-Susceptible; ${ }^{14}$ : Kp; ${ }^{15}$ : Carbapenem-Resistant;

16: Acinetobacter baumannii; ${ }^{17}$ : Pseudomonas aeruginosa; ${ }^{18}$ : Not Applicable. 


\subsection{Disk Diffusion (DD) and VP Assay}

The DD assay was used to evaluate the antimicrobial activity of the liquid phase in comparison to the analysis by VP assay used for the evaluation of the volatile compound activity. DD experiments showed a higher potency of TTO against Gram-negative bacteria than S. aureus. Regarding VP assays, the in-vitro effectiveness of TTO in VP was lower than that by DD analysis; nevertheless, TTO retained its activity against Gram-negatives, especially with regard to CR-Ab displaying 20 and $15 \mathrm{~mm}$ inhibition zone by means of DD and VP assays, respectively (Figure 1).

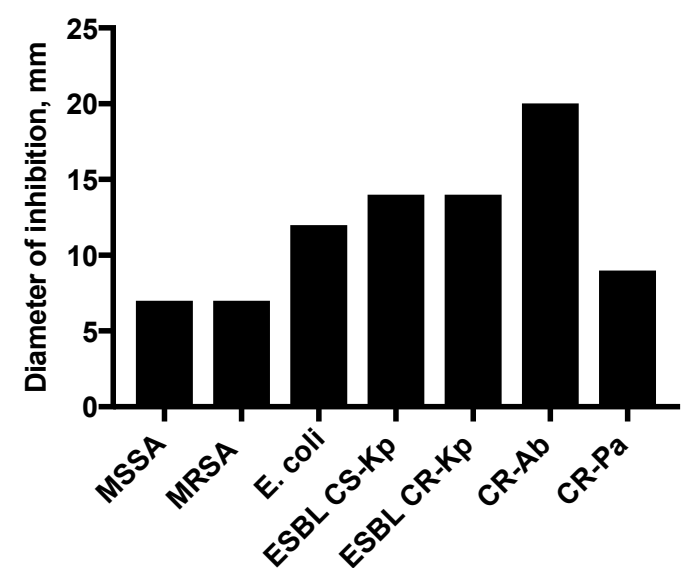

(A)

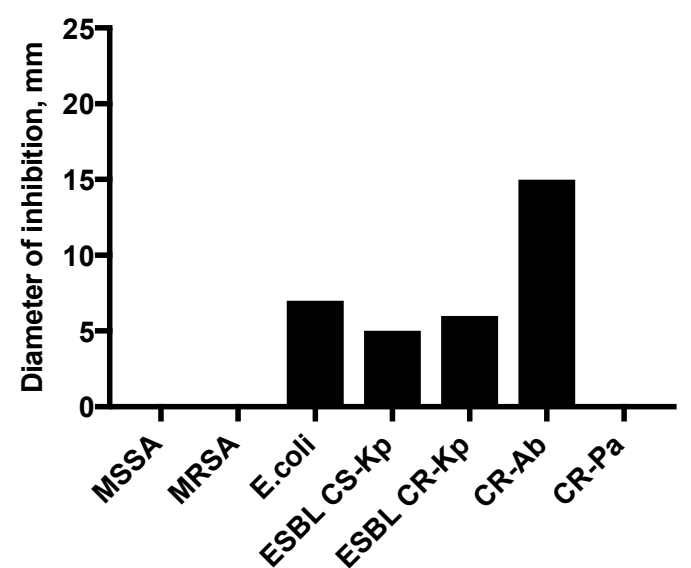

(B)

Figure 1. Disk diffusion (panel A) and vapor phase (panel B) activity of TTO. MSSA: Methicillin-susceptibility Staphylococcus aureus; MRSA: Methicillin-resistant Staphylococcus aureus; ESBL: Extended Spectrum Beta-Lactamases; CS: Carbapenem-Susceptible; CR: Carbapenem-Resistant; Kp: Klebsiella pneumoniae; Ab: Acinetobacter baumannii; Pa: Pseudomonas aeruginosa.

\subsection{Time Kill Studies}

In agreement with the MIC/MBC data, killing studies of TTO alone against MRSA showed a concentration-dependent effect, with an absence of bacterial growth at concentration of $2 \%$; on the other hand, only a bacteriostatic effect was noted at the concentrations of $1 \%$ and $0.5 \%$ and no activity was observed at $0.25 \%$ (Figure 2).

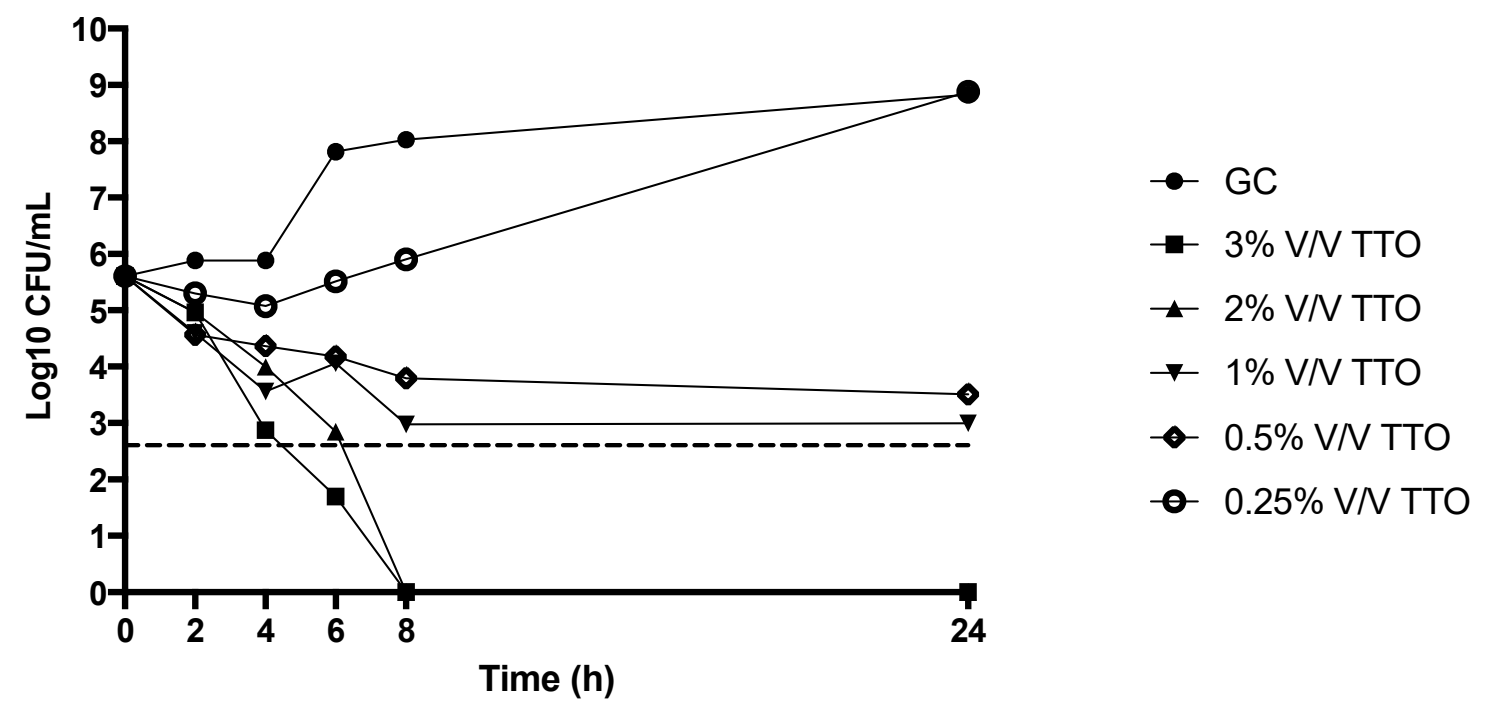

Figure 2. Activity of TTO against MRSA at different concentrations throughout killing study. GC: Growth Control; MRSA: Methicillin-resistant Staphylococcus aureus. Dashed line represents bactericidal activity. 
Interestingly, TTO associated with OXA was shown to lower the antibiotic MIC against MRSA, which was resistant to all antimicrobial beta-lactams. Evaluation of bactericidal and synergistic activity of TTO combined with OXA was therefore conducted at sub-inhibitory concentrations (Figure 3). TTO and OXA alone at sub-inhibitory concentrations $(0.25-0.5 \%$ and $1-2 \mu \mathrm{g} / \mathrm{mL}$, respectively) were not able to reduce the bacterial amount, whereas the combinations of TTO + OXA at the same concentrations with the exception of $0.25 \% \mathrm{TTO}+1 \mu \mathrm{g} / \mathrm{mL}$ OXA, showed marked synergistic effects and bactericidal activity against MRSA, with absence of any bacterial growth at $24 \mathrm{~h}$ (Figure 3).
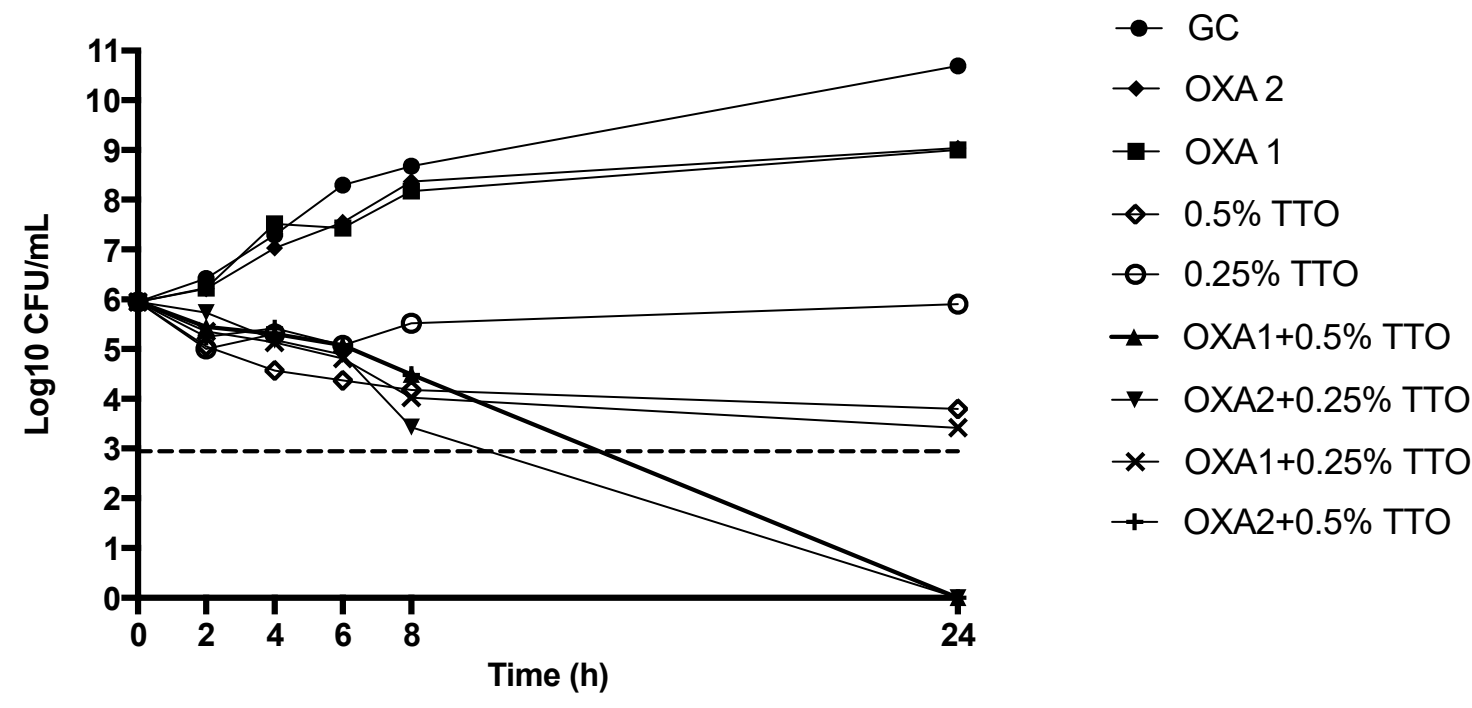

Figure 3. Activity of TTO $(v / v)$ and OXA $(\mu \mathrm{g} / \mathrm{mL})$ at different concentrations against MRSA throughout killing study. GC: Growth Control; MRSA: Methicillin-resistant Staphylococcus aureus; OXA: oxacillin. Dashed line represents bactericidal activity.

\section{Discussion}

The spread of multi-drug resistant bacteria is well recognized as an emergent global challenge, given the paucity of active therapeutical options and the high rate of mortality [2]. Thus, alternatives including natural substances are proposed as intriguing options for facing the problem of resistance in bacteria [24].

Based on these considerations, in the present study the antimicrobial activity of a commercial formulation of TTO was evaluated against S. aureus and several MDR Gram-negative bacteria.

This report demonstrates a remarkable bactericidal activity of TTO against all the tested MDR Gram-negatives with absence of bacterial growth at concentrations ranging from $0.25 \%$ to $0.5 \% v / v$ for E. coli, ESBL-CS-Kp, CR-Ab, and CR-Kp whereas a lower bactericidal activity $(1 \% v / v)$ was found for CR-Pa, in line with that observed in other studies and summarized by Carson et al., where most bacteria were susceptible to TTO at concentrations of $1.0 \%$ or less and higher MICs were reported for organisms such as P. aeruginosa [13].

To corroborate the TTO antimicrobial effectiveness, its synergistic activity was also investigated in combination with sub-inhibitory concentrations of traditional antimicrobials commonly used as a part of combination treatment against MDR Gram-negatives [25]. Among used antimicrobial MEM (to which all the CR strains were resistant) and COL (to which both CS and CR-Kp were resistant) a synergism was shown with all tested combinations, with FICI values lower than 0.5.

Other studies reported EOs' synergistic activities when used in combination with antibiotics [26-28]; nevertheless, to the best of our knowledge, this paper demonstrates for the first time a potent antimicrobial activity of TTO, alone and in combination with different antimicrobials, against clinically relevant MDR Gram-negatives strains (i.e., CR-Kp, CR-Ab, and CR-Pa) and even PDR Kp, towards which the available therapeutic options are very limited or absent. In fact, previous 
studies investigated the activity of EOs other than TTO against ESBL producing Gram-negatives with unknown sensitivity to carbapenems [24] or oregano EO against CR-Kp with unknown sensitivity to colistin $[29,30]$.

Thus, the results of the present study appear extremely promising for a potential clinical use of TTO in the setting of infections caused by MDR Gram-negative microorganisms.

In addition, being aware that hospital pneumonia cases are usually caused by MDR Gram-negative bacteria [31], the potency of TTO was also evaluated in the VP [32]. Even though the VP efficacy was globally lower than that observed with the disk diffusion analysis (liquid phase), antibacterial activity was retained against E. coli and both CS and CR-Kp whereas no activity was found with regard to MSSA, MRSA, and CR-Pa. Interestingly, TTO in VP maintained an elevated activity towards CR-Ab, thus corroborating the results obtained by Miao Li et al in their model of pulmonary delivery of tea tree oil-b-cyclodextrin inclusion complexes [33]. It seems that no VP assays have yet been performed against other MDR and PDR Gram-negatives. If confirmed, the observed effectiveness of TTO VP against $\mathrm{CR}-\mathrm{Ab}$ might have a critical clinical impact for the therapy of $\mathrm{CR}-\mathrm{Ab}$ lung infection.

Taking in to consideration these inspiring results, additional efforts should be undertaken for the implementation of TTO therapeutical use in the setting of MDR infections beyond cosmetics.

However, the irritant properties and the hydrophobicity of TTO might limit its clinical application [34]. Although there have been reports of cutaneous and oral toxicity related to TTO, its general toxicology (i.e., $\mathrm{LD}_{50}$ ) profile suggested that severe reactions would be extremely rare in the absence of ingestion [35]. Others found the effect of TTO on cell viability as primarily dose dependent, with significant cytotoxicity at concentrations of $\geq 10 \%$ and $\geq 50 \%$ for cell lines and whole tissue, respectively [36].

To counterpart these limitations, herein it was observed that the remarkable antibacterial activity was present at very low concentration and, when combined with commonly therapeutically used antimicrobials, even at sub-inhibitory concentrations, thus making it reasonable to have further investigations on the best TTO percentage to be used for clinical purpose. On the other hand, a recent study performed in an animal model of bacterial and fungal pneumonia showed the efficacy of inhalable TTO nanoemulsion as a promising and intriguing local therapy to overcome difficulties in TTO formulation [37].

As well as for Gram-negative bacteria, local and systemic infections caused by MRSA represent a therapeutical challenge for physicians [38]. The present investigation showed that the addition of TTO at OXA sub-inhibitory concentrations was able to be reduced from 64 to $2 \mu \mathrm{g} / \mathrm{mL}$ its $\mathrm{MIC}$, being OXA one of the more active beta-lactam against $S$. aureus but to which MRSA is typically resistant [39]. Killing studies confirmed that low concentrations of TTO $(0.25-0.5 \% v / v)$ combined with OXA at concentrations equal to $(2 \mu \mathrm{g} / \mathrm{mL})$ and just lower than $(1 \mu \mathrm{g} / \mathrm{mL})$, the breakpoint for methicillin-susceptibility, obtained a potent concentration-dependent bactericidal and synergistic activity, with absence of bacterial growth after $24 \mathrm{~h}$ of antibiotic challenge. Although the MIC/MBC values of TTO against MSSA/MRSA were comparable with those obtained by a previous study [16], the killing results were slightly different, possibly due to the different concentrations used for the experiments (up to 3\% compared with 5\% v/v) [40]. Herein reported synergistic analyses confirmed the indifference between TTO and VAN, as previously described [15], whereas the novelty of this report is based on the observation (by both synergistic and killing studies) that the addition of TTO at sub-inhibitory concentration indeed restored MRSA sensitivity to OXA. Based on literature survey, no similar results have been yet described with TTO and MRSA and they appear to be crucial when considering the possibility of combining TTO with beta-lactams for MRSA infection. In fact, the activity of other EOs was evaluated against several MRSA strains [41,42] and the tendency of EOs to reduce antibiotic resistance was observed, with the combination natural compounds-synthetic drugs inducing the reversal of resistance in bacteria toward antibiotics such as penicillin [4], ampicillin/sulbactam [5], carbapenems [43], and oxacillin [44]. The mode of action of antimicrobial combination leading to the 
synergism is still an area of active research and it is probably attributed to the perturbation of bacterial membrane or the inhibition of PBP2a activity or its reduction [44] exerted by natural compounds.

Given the anti MRSA activity, the potential clinical application of TTO might reside on the local administration of the drug (either at a fixed $\% v / v$ or vehiculated by the use of nanoparticles) for the treatment of skin and soft tissue infections, including those occurring after surgery $[35,45]$ or nasal decolonization in the case of resistance to mupirocin or other treatments [46].

Because the reported differences in the antimicrobial activity of TTO could relate to the specific composition of the volatile compounds in the TTO, one of the strengths of this report was the combination of the chemical analysis of TTO components together with the evaluation of its antimicrobial activity both in liquid and VP. In particular, it has been reported that the antimicrobial activity of TTO is attributed mainly to terpinen-4-ol, which is the major component of the oil [47] and exhibits a favorable hydrophobic/hydrophilic profile [47]. Several studies on terpinen-4-ol have shown it to be a bactericidal agent. Ferrini et al. [48] reported its activity against strains resistant to mupirocin, fusidic acid, vancomycin, methicillin, and linezolid. In their article the terpinen-4-ol antistaphylococcal potency was found even higher than that of some antibiotics. In a different report the antimicrobial potency of some TTO chemical components was performed, including the terpinen-4-ol, by using disc diffusion and broth microdilution methods [13]. Terpinen-4-ol compared to the other components was found active against all tested microorganisms including Escherichia coli, Candida albicans, and Staphylococcus aureus. In the present study, the direct comparison of the two analyses (liquid and VP) indicated a marked increase in the percentage of $\alpha$-pinene and a marked reduction in terpinen-4-ol percentage in the VP compared to that observed in the liquid phase. This difference could be responsible for the higher biological effects of liquid TTO, especially against Gram-positive bacteria. In addition, it is of note that the greatest effects were observed with eucalyptol, a component often considered to have marginal antimicrobial activity. Even in the present study, we confirmed that eucalyptol was highly represented in liquid as well as in VP, raising the possibility that even if eucalyptol may not be one of the primary antimicrobial components, it might contribute to the permeabilization of bacterial membranes and thus facilitate the entry of other and more active components [47].

As expected, head space analysis showed that the lightest components ( $\alpha$-pinene, $\beta$-pinene) were more represented than the heaviest ones (terpinen-4-ol, $\alpha$-terpineol). This phenomenon was particularly evident for $\alpha$-pinene, leading to the speculation that it might contribute to the high antibacterial activity of TTO in VP against CR-Ab. However, the presence of other trace components could also be important, given that they could act synergistically to exert the antimicrobial action.

Taken together, these findings support the hypothesis that TTO comprise a large number of components and it is likely that their mode of action involves several targets in the bacterial cell [49]. The observed different antimicrobial activity might depend on the different percentage of TTO components in liquid as well in VP assays, suggesting that additional investigations on the activity of a specific component against a specific microorganism should be further encouraged.

Finally, it should be noted that the TTO used in the present study was a commercial formulation; thus, the results herein described might be an expression of one specific TTO and not of all TTOs. Nevertheless, in order to overcome this limitation, the chemical composition of the used commercial formulation was widely investigated, both in liquid and VP.

\section{Materials and Method}

\subsection{Antimicrobials Agents and TTO}

Antimicrobial agents were provided as purified powder by the manufacturer (Sigma Aldrich, Rome, Italy). Stock solutions at different concentrations were prepared in sterile and pyrogen-free $0.9 \%$ saline or water, according to the manufacturer's instructions. The activity of the tested antimicrobials 
was expressed as $\mu \mathrm{g} / \mathrm{mL}$ whereas the activity of TTO was expressed as $\% v / v$. The used TTO was commercially acquired as a pure and natural commercial formulation (ESPERIS S. P. A. Milan, Italy).

\subsection{TTO Chemical Composition Analysis}

The GC/MS analysis was carried out with a GC-MS and GC-FID using a turbomass Clarus 500 GC-MS/GC-FID from Perkin Elmer instruments (Waltham, MA, USA). A Stabilwax fused-silica capillary column (Restek, Bellefonte, PA, USA) (60 m $\times 0.25 \mathrm{~mm}, 0.25 \mathrm{~mm}$ film thickness) was used with helium as carrier gas $(1.0 \mathrm{~mL} / \mathrm{min})$. GC oven temperature was kept at $60{ }^{\circ} \mathrm{C}$ for $5 \mathrm{~min}$ and programmed to $220^{\circ} \mathrm{C}$ at a rate of $5^{\circ} \mathrm{C} / \mathrm{min}$ and kept constant at $220^{\circ} \mathrm{C}$ for $30 \mathrm{~min}$. Solvent delay 0-2 min and scan time $0.2 \mathrm{~s}$. MS was taken at $70 \mathrm{eV}$. Mass range was from 30 to $350 \mathrm{~m} / \mathrm{z}$. $1 \mu \mathrm{L}$ of TTO was diluted in $1 \mathrm{~mL}$ of methanol and $1 \mu \mathrm{L}$ of the solution was injected into the GC injector at a temperature of $280{ }^{\circ} \mathrm{C}$.

To investigate TTO volatile component, a Perkin-Elmer Headspace (HS) Turbomatrix 40 autosampler connected to a Clarus 500 GC-MS was used for headspace analysis. To develop an optimal headspace procedure for the determination of volatile organic compounds (VOCs) from TTO, essential parameters such as equilibration time and temperature were adjusted.

The relative percentages for quantification of the components were calculated by electronic integration of the GC-FID peak areas. Identification of the constituents was performed based on MS library search (Nist MS Search Ver. 2.0 and Wiley 9th edition). Linear retention indices (LRI) of each compound were calculated using a mixture of aliphatic hydrocarbons (C8-C30, Ultrasci) injected directly into the GC injector with the same temperature program as reported above. Only chemical components with percentages higher that $0.1 \%$ were investigated (Table 1 ).

\subsection{Bacterial Strains}

For antimicrobial activity determination, we used the following microorganisms: MSSA (ATCC 29213), E. coli (ATCC 25922), MRSA (clinical strain isolated from skin), ESBL-CS-Kp (clinical strain isolated from urine), ESBL-CR-Kp (clinical strain isolated from urine), CR-Ab (clinical strain isolated from sputum) and CR-Pa (clinical strain isolated from bronchoalveolar lavage).

After bacterial storage on cryovial bead preservation system (Microbank; Pro-Lab Diagnostics, Richmond Hill, ON, Canada) at $-80^{\circ} \mathrm{C}$, inoculum was prepared by spreading one cryovial bead on blood agar plate and incubating overnight at $37^{\circ} \mathrm{C}$. One colony was re-suspended in $5 \mathrm{~mL}$ tryptic soy broth (TSB) and incubated at $37^{\circ} \mathrm{C}$ without shaking. Overnight cultures were then adjusted to a turbidity of $0.5 \mathrm{McF}$ arland, corresponding to $\approx 1 \times 10^{8} \mathrm{CFU} / \mathrm{mL}$.

\subsection{Antimicrobial Activity}

MIC and MBC of TTO, amikacin (AMK), cefazolin (CFZ), meropenem (MEM), oxacillin (OXA), colistin (COL), rifampin (RIF), and vancomicin (VAN) were determined by using the macro dilution broth method [50]. Briefly, two-fold serial dilutions of each antimicrobial agent and TTO were prepared in $2 \mathrm{~mL}$ Mueller Hinton broth (MHB) in borosilicate glass tubes and incubated for $24 \mathrm{~h}$ at $37^{\circ} \mathrm{C}$. MIC was defined as the lowest concentration of antibiotic that completely inhibited visible growth whereas bactericidal activity was defined as $\geq 3-\log 10 \mathrm{CFU} / \mathrm{ml}$ reduction of the initial bacterial count after $24 \mathrm{~h}$ of incubation. The used bacterial inoculum was $\sim 5 \times 10^{5} \mathrm{CFU} / \mathrm{mL}$.

\subsection{Synergistic Activity of TTO Combined with Antimicrobial Agents}

Checkerboard method was used to investigate the synergism of the following combinations: $\mathrm{TTO}+\mathrm{AMK} / \mathrm{CFZ} / \mathrm{OXA} / \mathrm{VAN} / \mathrm{RIF}$ for MSSA/MRSA; TTO + AMK/MEM for E. coli; $\mathrm{TTO}+\mathrm{MEM} / \mathrm{COL}$ for CR-Ab; TTO + MEM/AMK/COL for CR-Pa; TTO + AMK/MEM/COL for ESBL-CS-Kp and CR-Kp. A 96-well microtitre plate containing TTO/antibiotic combinations at different concentrations $(1-0.5-0.25 \% v / v$ and $0.5,0.25,0.125 \times \mathrm{MIC}$, respectively) was used to perform checkerboard synergy testing. Wells containing a final inoculum of $\sim 5 \times 10^{5} \mathrm{CFU} / \mathrm{mL}$ were 
incubated at $37^{\circ} \mathrm{C}$ for $24 \mathrm{~h}$ under static conditions in $\mathrm{MHB}$. The fractional inhibitory concentration index (FICI) of each combination was defined as: $\sum \mathrm{FIC}$ : FICA + FICB = MICA + B $/ \mathrm{MICA}$ alone + MICB $+\mathrm{A} / \mathrm{MICBalone}$. Synergism was defined as FICI $\leq 0.5$ whereas FICI $>0.5$ but $<4$ were considered as indifferent.

\subsection{DD and VP Assay}

The antimicrobial activity of TTO was compared against the same selection of antibiotic-resistant and -sensitive bacterial strains described above by using DD and VP assays.

For DD analysis, $10 \mu \mathrm{L}$ of absolute $(100 \% v / v)$ TTO were inoculated onto individual 6-mm filter paper discs and placed on Mueller Hinton Agar (MHA) plates containing $\sim 1.5 \times 10^{8} \mathrm{CFU} / \mathrm{mL}$ of the tested bacteria whereas for VP, TTO-impregnated (concentration as above) discs were placed on the lid of the petri dish and covered with parafilm, as previously described [51] so that only the TTO vapor fraction was responsible for organism inhibition.

The antimicrobial effect was assessed by measuring the inhibition zone (expressed as $\mathrm{mm}$ ) after $24 \mathrm{~h}$ of incubation at $37^{\circ} \mathrm{C}$.

\subsection{Time-Kill Studies}

Given the unexpected effect of TTO in lowering OXA MIC against MRSA, which is resistant to all beta-lactam antimicrobials, the activity of TTO alone and in combination with OXA was evaluated by time-kill studies performed in the logarithmic growth phase using an initial inoculum of $\sim 5 \times 10^{5} \mathrm{CFU} / \mathrm{mL}$.

Killing curves were performed in boro-silicate glass tubes in a final volume of $10 \mathrm{~mL}$ CAMHB which were further incubated at $37^{\circ} \mathrm{C}$. At 2, 4, 6, 8, and $24 \mathrm{~h}$ time points, $1 \mathrm{~mL}$ aliquots were sampled and washed with $0.9 \%$ saline solution in order to prevent the antibiotic carry-over effect. Ten-fold dilutions were then plated on Muller-Hinton agar and the number of CFUs was determined. Medium without antibiotics was used as growth control. Bactericidal activity was defined as $\geq 99.9 \%$ (i.e., $\geq 3-\log 10 \mathrm{CFU} / \mathrm{mL}$ ) reduction of the initial bacterial count at each time point. Synergy was defined as $\mathrm{a} \geq 100$-fold decrease in $\mathrm{CFU} / \mathrm{mL}$ between the combination and its most active constituent at the same concentration after $24 \mathrm{~h}$, with the number of surviving organisms in the presence of the combination $\geq 100$-fold CFU $/ \mathrm{mL}$ below the starting inoculum.

For TTO alone we used 3\%, 2\%, 1\%, 0.5\%, and $0.25 \% v / v$ whereas when tested in combination with OXA, we used the following concentrations: OXA $2 \mu \mathrm{g} / \mathrm{mL}(0.06 \times \mathrm{MIC}), \mathrm{OXA} 1 \mu \mathrm{g} / \mathrm{mL}(0.03 \times \mathrm{MIC})$, OXA $2 \mu \mathrm{g} / \mathrm{mL}(0.06 \times \mathrm{MIC})+$ TTO $0.5 \%$, OXA $2 \mu \mathrm{g} / \mathrm{mL}(0.06 \times \mathrm{MIC})+\mathrm{TTO} 0.25 \%, \mathrm{OXA} 1 \mu \mathrm{g} / \mathrm{mL}$ $(0.03 \times \mathrm{MIC})+$ TTO $0.25 \%$, OXA $1 \mu \mathrm{g} / \mathrm{mL}(0.03 \times \mathrm{MIC})+\mathrm{TTO} 0.25 \%$.

All in-vitro experiments were performed in duplicate.

\section{Conclusions}

In conclusion (a) for the first time a significant potency of TTO (alone and in combination) was demonstrated against a selection of clinically relevant MDR/PDR Gram-negative microorganisms; (b) the antibacterial evaluation of TTO was performed both in liquid and VP, making it reasonable to be used as a possible inhalatory for lung infections, especially those caused by CR-Ab; (c) the activity of TTO/OXA combination against MRSA at sub-inhibitory concentrations might be expression of a restored susceptibility to OXA induced by TTO, with obvious clinical implications.

Taken together, the herein reported results might provide the basis for a possible role of TTO as part of non-conventional regimens against both MSSA/MRSA and Gram-negative MDR/PDR microorganisms. However, since several different varieties of TTO have been described so far [52] and given that in the present study only one type of TTO was thoroughly investigated, the results of the present research might be considered as a potential starting-point for additional studies on the activity of TTO against multi-drug resistant bacteria. 
Author Contributions: A.O. and R.R. conceived and initiated the work. A.O. planned the experiments and drafted the manuscript. S.G. performed the chemical composition analyses. A.O., M.B., M.D.A., S.C., M.T.M. collected the bacterial strains and performed the microbiology experiments. A.O., R.R. and V.V. reviewed and edited the manuscript. All the authors critically edited the manuscript before submission.

Funding: This work was supported by a grant of "Sapienza" University of Rome, 2014 (Number: C26N14S7RB).

Acknowledgments: The authors thank the technical staff for their contribution in laboratory sample collection and processing.

Conflicts of Interest: The authors declare no conflict of interest.

Data Availability Statement: The data used to support the findings of this study are available from the corresponding author upon request.

\section{Abbreviations}

\begin{tabular}{|c|c|}
\hline MDR & multidrug-resistant \\
\hline $\mathrm{CR}$ & carbapenem-resistant \\
\hline EOs & essential oils \\
\hline TTO & Tea tree oil \\
\hline MSSA & methicillin-susceptible Staphylococus aureus \\
\hline MRSA & methicillin-resistant Staphylococus aureus \\
\hline ESBL & extended-spectrum beta lactamases \\
\hline CS & carbapenem-sensitive \\
\hline $\mathrm{Kp}$ & Klebsiella pneumoniae \\
\hline $\mathrm{Ab}$ & Acinetobacter baumannii \\
\hline $\mathrm{Pa}$ & Pseudomonas aeruginosa \\
\hline HS & Headspace \\
\hline VOCs & volatile organic compounds \\
\hline LRI & Linear retention indices \\
\hline TSB & tryptic soy broth \\
\hline $\mathrm{MIC}$ & minimal inhibitory concentration \\
\hline MBC & minimal bactericidal concentration \\
\hline AMK & amikacin \\
\hline CFZ & cefazolin \\
\hline MEM & meropenem \\
\hline OXA & oxacillin \\
\hline $\mathrm{COL}$ & colistin \\
\hline RIF & rifampin \\
\hline VAN & vancomicin \\
\hline MHB & Mueller Hinton Broth \\
\hline FICI & fractional inhibitory concentration index \\
\hline $\mathrm{DD}$ & disk diffusion \\
\hline $\mathrm{VP}$ & vapour phase \\
\hline MHA & Mueller Hinton Agar \\
\hline CFUs & Colony Forming Units \\
\hline PDR & pan-drug resistant \\
\hline
\end{tabular}

\section{References}

1. Munoz-Price, L.S.; Poirel, L.; Bonomo, R.A.; Schwaber, M.J.; Daikos, G.L.; Cormican, M.; Cornaglia, G.; Garau, J.; Gniadkowski, M.; Hayden, M.K.; et al. Clinical epidemiology of the global expansion of Klebsiella pneumoniae carbapenemases. Lancet Infect. Dis. 2013, 13, 785-796. [CrossRef]

2. Falagas, M.E.; Mavroudis, A.D.; Vardakas, K.Z. The antibiotic pipeline for multi-drug resistant gram negative bacteria: What can we expect? Expert Rev. Anti. Infect. Ther. 2016, 14, 747-763. [CrossRef] [PubMed]

3. Schelz, Z.; Molnar, J.; Hohmann, J. Antimicrobial and antiplasmid activities of essential oils. Fitoterapia 2006, 77, 279-285. [CrossRef] [PubMed] 
4. Zhao, W.H.; Hu, Z.Q.; Hara, Y.; Shimamura, T. Inhibition of penicillinase by epigallocatechin gallate resulting in restoration of antibacterial activity of penicillin against penicillinase-producing Staphylococcus aureus. Antimicrob. Agents Chemother. 2002, 46, 2266-2268. [CrossRef] [PubMed]

5. Hu, Z.Q.; Zhao, W.H.; Hara, Y.; Shimamura, T. Epigallocatechin gallate synergy with ampicillin/sulbactam against 28 clinical isolates of methicillin-resistant Staphylococcus aureus. J. Antimicrob. Chemother. 2001, 48, 361-364. [CrossRef] [PubMed]

6. Orhan, I.E.; Ozcelik, B.; Kan, Y.; Kartal, M. Inhibitory Effects of Various Essential Oils and Individual Components against Extended-Spectrum Beta-Lactamase (ESBL) Produced by Klebsiella pneumoniae and Their Chemical Compositions. J. Food Sci. 2011, 76, M538-M546. [CrossRef] [PubMed]

7. Bajpai, V.K.; Sharma, A.; Baek, K.-H. Antibacterial mode of action of Cudrania tricuspidata fruit essential oil, affecting membrane permeability and surface characteristics of food-borne pathogens. Food Control 2013, 32, 582-590. [CrossRef]

8. Azhdarzadeh, F.; Hojjati, M. Chemical Composition and Antimicrobial Activity of Leaf, Ripe and Unripe Peel of Bitter Orange (Citrus aurantium) Essential Oils. Nutr. Food Sci. Res. 2016, 3, 43-50. [CrossRef]

9. Okoh, O.O.; Sadimenko, A.P.; Afolayan, A.J. Comparative evaluation of the antibacterial activities of the essential oils of Rosmarinus officinalis L. obtained by hydrodistillation and solvent free microwave extraction methods. Food Chem. 2010, 120, 308-312. [CrossRef]

10. Tadic, V.; Oliva, A.; Bozovic, M.; Cipolla, A.; De Angelis, M.; Vullo, V.; Garzoli, S.; Ragno, R. Chemical and Antimicrobial Analyses of Sideritis romana L. subsp. purpurea (Tal. ex Benth.) Heywood, an Endemic of the Western Balkan. Molecules 2017, 22, 1395. [CrossRef]

11. Trombetta, D.; Castelli, F.; Sarpietro, M.G.; Venuti, V.; Cristani, M.; Daniele, C.; Saija, A.; Mazzanti, G.; Bisignano, G. Mechanisms of Antibacterial Action of Three Monoterpenes. Antimicrob. Agents Chemother. 2005, 49, 2474-2478. [CrossRef] [PubMed]

12. Sailer, R.; Berger, T.; Reichling, J.; Harkenthal, M. Pharmaceutical and medicinal aspects of Australian tea tree oil. Phytomedicine 1998, 5, 489-495. [CrossRef]

13. Carson, C.F.; Cookson, B.D.; Farrelly, H.D.; Riley, T.V. Susceptibility of methicillin-resistant Staphylococcus aureus to the essential oil of Melaleuca alternifolia. J. Antimicrob. Chemother. 1995, 35, 421-424. [CrossRef] [PubMed]

14. Cox, S.D.; Mann, C.M.; Markham, J.L.; Bell, H.C.; Gustafson, J.E.; Warmington, J.R.; Wyllie, S.G. The mode of antimicrobial action of the essential oil of Melaleuca alternifolia (tea tree oil). J. Appl. Microbiol. 2000, 88, 170-175. [CrossRef] [PubMed]

15. LaPlante, K.L. In vitro activity of lysostaphin, mupirocin, and tea tree oil against clinical methicillin-resistant Staphylococcus aureus. Diagn. Microbiol. Infect. Dis. 2007, 57, 413-418. [CrossRef] [PubMed]

16. D'Arrigo, M.; Ginestra, G.; Mandalari, G.; Furneri, P.M.; Bisignano, G. Synergism and postantibiotic effect of tobramycin and Melaleuca alternifolia (tea tree) oil against Staphylococcus aureus and Escherichia coli. Phytomedicine 2010, 17, 317-322. [CrossRef] [PubMed]

17. Rai, M.; Paralikar, P.; Jogee, P.; Agarkar, G.; Ingle, A.P.; Derita, M.; Zacchino, S. Synergistic antimicrobial potential of essential oils in combination with nanoparticles: Emerging trends and future perspectives. Int. J. Pharm. 2017, 519, 67-78. [CrossRef] [PubMed]

18. Artini, M.; Patsilinakos, A.; Papa, R.; Bozovic, M.; Sabatino, M.; Garzoli, S.; Vrenna, G.; Tilotta, M.; Pepi, F.; Ragno, R.; et al. Antimicrobial and Antibiofilm Activity and Machine Learning Classification Analysis of Essential Oils from Different Mediterranean Plants against Pseudomonas aeruginosa. Molecules 2018, 23, 482. [CrossRef] [PubMed]

19. Bozovic, M.; Garzoli, S.; Sabatino, M.; Pepi, F.; Baldisserotto, A.; Andreotti, E.; Romagnoli, C.; Mai, A.; Manfredini, S.; Ragno, R. Essential Oil Extraction, Chemical Analysis and Anti-Candida Activity of Calamintha nepeta (L.) Savi subsp. glandulosa (Req.) Ball-New Approaches. Molecules 2017, 22, 203. [CrossRef]

20. Bozovic, M.; Navarra, A.; Garzoli, S.; Pepi, F.; Ragno, R. Esential oils extraction: A 24-hour steam distillation systematic methodology. Nat. Prod. Res. 2017, 31, 2387-2396. [CrossRef] [PubMed]

21. Garzoli, S.; Bozovic, M.; Baldisserotto, A.; Andreotti, E.; Pepi, F.; Tadic, V.; Manfredini, S.; Ragno, R. Sideritis romana L. subsp. purpurea (Tal. ex Benth.) Heywood, a new chemotype from Montenegro. Nat. Prod. Res. 2018, 32, 1056-1061. [PubMed] 
22. Garzoli, S.; Bozovic, M.; Baldisserotto, A.; Sabatino, M.; Cesa, S.; Pepi, F.; Vicentini, C.B.; Manfredini, S.; Ragno, R. Essential oil extraction, chemical analysis and anti-Candida activity of Foeniculum vulgare Miller-New approaches. Nat. Prod. Res. 2018, 32, 1254-1259. [CrossRef] [PubMed]

23. Venditti, A.; Frezza, C.; Salutari, G.; Cecco, M.d.; Ciaschetti, G.; Oliva, A.B.; Angelis, M.D.; Vullo, V.; Sabatino, M.; Garzoli, S.; et al. Composition of the Essential Oil of Coristospermum cuneifolium and Antimicrobial Activity Evaluation. Planta Med. Int. Open 2017, 4, e74-e81. [CrossRef]

24. Warnke, P.H.; Lott, A.J.; Sherry, E.; Wiltfang, J.; Podschun, R. The ongoing battle against multi-resistant strains: In-vitro inhibition of hospital-acquired MRSA, VRE, Pseudomonas, ESBL E. coli and Klebsiella species in the presence of plant-derived antiseptic oils. J. Craniomaxillofac. Surg. 2013, 41, 321-326. [PubMed]

25. Oliva, A.; Scorzolini, L.; Cipolla, A.; Mascellino, M.T.; Cancelli, F.; Castaldi, D.; D'Abramo, A.; D'Agostino, C.; Russo, G.; Ciardi, M.R.; et al. In vitro evaluation of different antimicrobial combinations against carbapenemase-producing Klebsiella pneumoniae: The activity of the double-carbapenem regimen is related to meropenem MIC value. J. Antimicrob. Chemother. 2017, 72, 1981-1984. [CrossRef] [PubMed]

26. Duarte, A.; Ferreira, S.; Silva, F.; Domingues, F.C. Synergistic activity of coriander oil and conventional antibiotics against Acinetobacter baumannii. Phytomedicine 2012, 19, 236-238. [CrossRef] [PubMed]

27. Duarte, A.E.; de Menezes, I.R.; Bezerra Morais Braga, M.F.; Leite, N.F.; Barros, L.M.; Waczuk, E.P.; Pessoa da Silva, M.A.; Boligon, A.; Teixeira Rocha, J.B.; Souza, D.O.; et al. Antimicrobial Activity and Modulatory Effect of Essential Oil from the Leaf of Rhaphiodon echinus (Nees \& Mart) Schauer on Some Antimicrobial Drugs. Molecules 2016, 21, 743. [CrossRef]

28. Mulyaningsih, S.; Sporer, F.; Zimmermann, S.; Reichling, J.; Wink, M. Synergistic properties of the terpenoids aromadendrene and 1,8-cineole from the essential oil of Eucalyptus globulus against antibiotic-susceptible and antibiotic-resistant pathogens. Phytomedicine 2010, 17, 1061-1066. [CrossRef] [PubMed]

29. Fournomiti, M.; Kimbaris, A.; Mantzourani, I.; Plessas, S.; Theodoridou, I.; Papaemmanouil, V.; Kapsiotis, I.; Panopoulou, M.; Stavropoulou, E.; Bezirtzoglou, E.E.; et al. Antimicrobial activity of essential oils of cultivated oregano (Origanum vulgare), sage (Salvia officinalis), and thyme (Thymus vulgaris) against clinical isolates of Escherichia coli, Klebsiella oxytoca, and Klebsiella pneumoniae. Microb. Ecol. Health Dis. 2015, 26, 23289. [CrossRef] [PubMed]

30. Scandorieiro, S.; de Camargo, L.C.; Lancheros, C.A.; Yamada-Ogatta, S.F.; Nakamura, C.V.; de Oliveira, A.G.; Andrade, C.G.; Duran, N.; Nakazato, G.; Kobayashi, R.K. Synergistic and Additive Effect of Oregano Essential Oil and Biological Silver Nanoparticles against Multidrug-Resistant Bacterial Strains. Front. Microbiol. 2016, 7, 760. [CrossRef] [PubMed]

31. Ekren, P.K.; Ranzani, O.T.; Ceccato, A.; Li Bassi, G.; Munoz Conejero, E.; Ferrer, M.; Niederman, M.S.; Torres, A. Evaluation of the 2016 Infectious Diseases Society of America/American Thoracic Society Guideline Criteria for Risk of Multi-drug Resistant Pathogens in Hospital-acquired and Ventilator-associated Pneumonia Patients in the Intensive Care Unit. Am. J. Respir. Crit. Care Med. 2017, 197, 826-830. [CrossRef] [PubMed]

32. Doran, A.L.; Morden, W.E.; Dunn, K.; Edwards-Jones, V. Vapour-phase activities of essential oils against antibiotic sensitive and resistant bacteria including MRSA. Lett. Appl. Microbiol. 2009, 48, 387-392. [CrossRef] [PubMed]

33. Li, M.; Zhu, L.; Zhang, T.; Liu, B.; Du, L.; Jin, Y. Pulmonary delivery of tea tree oil-beta-cyclodextrin inclusion complexes for the treatment of fungal and bacterial pneumonia. J. Pharm. Pharmacol. 2017, 69, 1458-1467. [CrossRef] [PubMed]

34. Hammer, K.A.; Carson, C.F.; Riley, T.V.; Nielsen, J.B. A review of the toxicity of Melaleuca alternifolia (tea tree) oil. Food Chem. Toxicol. 2006, 44, 616-625. [CrossRef] [PubMed]

35. Halcon, L.; Milkus, K. Staphylococcus aureus and wounds: A review of tea tree oil as a promising antimicrobial. Am. J. Infect. Control. 2004, 32, 402-408. [CrossRef] [PubMed]

36. Homeyer, D.C.; Sanchez, C.J.; Mende, K.; Beckius, M.L.; Murray, C.K.; Wenke, J.C.; Akers, K.S. In vitro activity of Melaleuca alternifolia (tea tree) oil on filamentous fungi and toxicity to human cells. Med. Mycol. 2015, 53, 285-294. [CrossRef] [PubMed]

37. Li, M.; Zhu, L.; Liu, B.; Du, L.; Jia, X.; Han, L.; Jin, Y. Tea tree oil nanoemulsions for inhalation therapies of bacterial and fungal pneumonia. Colloids Surf. B Biointerfaces 2016, 141, 408-416. [CrossRef] [PubMed]

38. Calfee, D.P. Trends in Community Versus Health Care-Acquired Methicillin-Resistant Staphylococcus aureus Infections. Curr. Infect. Dis. Rep. 2017, 19, 48. [CrossRef] [PubMed] 
39. David, M.Z.; Daum, R.S. Treatment of Staphylococcus aureus Infections. Curr. Top. Microbiol. Immunol. 2017, 409, 325-383. [PubMed]

40. Loughlin, R.; Gilmore, B.F.; McCarron, P.A.; Tunney, M.M. Comparison of the cidal activity of tea tree oil and terpinen-4-ol against clinical bacterial skin isolates and human fibroblast cells. Lett. Appl. Microbiol. 2008, 46, 428-433. [CrossRef] [PubMed]

41. Gibbons, S. Phytochemicals for Bacterial Resistance-Strengths, Weaknesses and Opportunities. Planta Med. 2008, 74, 594-602. [CrossRef] [PubMed]

42. Lahmar, A.; Bedoui, A.; Mokdad-Bzeouich, I.; Dhaouifi, Z.; Kalboussi, Z.; Cheraif, I.; Ghedira, K.; Chekir-Ghedira, L. Reversal of resistance in bacteria underlies synergistic effect of essential oils with conventional antibiotics. Microb. Pathog. 2017, 106, 50-59. [CrossRef] [PubMed]

43. Hu, Z.Q.; Zhao, W.H.; Asano, N.; Yoda, Y.; Hara, Y.; Shimamura, T. Epigallocatechin gallate synergistically enhances the activity of carbapenems against methicillin-resistant Staphylococcus aureus. Antimicrob. Agents Chemother. 2002, 46, 558-560. [CrossRef] [PubMed]

44. Shimizu, M.; Shiota, S.; Mizushima, T.; Ito, H.; Hatano, T.; Yoshida, T.; Tsuchiya, T. Marked potentiation of activity of beta-lactams against methicillin-resistant Staphylococcus aureus by corilagin. Antimicrob. Agents Chemother. 2001, 45, 3198-3201. [CrossRef] [PubMed]

45. Edmondson, M.; Newall, N.; Carville, K.; Smith, J.; Riley, T.V.; Carson, C.F. Uncontrolled, open-label, pilot study of tea tree (Melaleuca alternifolia) oil solution in the decolonisation of methicillin-resistant Staphylococcus aureus positive wounds and its influence on wound healing. Int. Wound J. 2011, 8, 375-384. [CrossRef] [PubMed]

46. Septimus, E.J.; Schweizer, M.L. Decolonization in Prevention of Health Care-Associated Infections. Clin. Microbiol. Rev. 2016, 29, 201-222. [CrossRef] [PubMed]

47. Carson, C.F.; Hammer, K.A.; Riley, T.V. Melaleuca alternifolia (Tea Tree) Oil: A Review of Antimicrobial and Other Medicinal Properties. Clin. Microbiol. Rev. 2006, 19, 50-62. [CrossRef] [PubMed]

48. Ferrini, A.M.; Mannoni, V.; Aureli, P.; Salvatore, G.; Piccirillp, E.; Ceddia, T.; Pontieri, E.; Sessa, R.; Oliva, B. Melaleuca Alternifolia Essential Oil Possesses Potent Anti-Staphylococcal Activity Extended to Strains Resistant to Antibiotics. Int. J. Immunopathol. Pharmacol. 2006, 19, 539-544. [CrossRef] [PubMed]

49. Burt, S. Essential oils: Their antibacterial properties and potential applications in foods-A review. Int. J. Food Microbiol. 2004, 94, 223-253. [CrossRef] [PubMed]

50. CLSI. Methods for Dilution Antimicrobial Susceptibility Tests for Bacteria that Grow Aerobically; Approved Standard; Document M7-A7; CLSI: Wayne, PA, USA, 2006.

51. Oliva, A.; Gizzi, F.; Mascellino, M.T.; Cipolla, A.; D’Abramo, A.; D’Agostino, C.; Trinchieri, V.; Russo, G.; Tierno, F.; Iannetta, M.; et al. Bactericidal and synergistic activity of double-carbapenem regimen for infections caused by carbapenemase-producing Klebsiella pneumoniae. Clin. Microbiol. Infect. 2016, 22, 147-153. [CrossRef] [PubMed]

52. Homer, L.E.; Leach, D.N.; Lea, D.; Slade Lee, L.; Henry, R.J.; Baverstock, P.R. Natural variation in the essential oil content of Melaleuca alternifolia Cheel (Myrtaceae). Biochem. Syst. Ecol. 2000, 28, 367-382. [CrossRef]

Sample Availability: Samples of the used TTO are available from the authors.

(C) 2018 by the authors. Licensee MDPI, Basel, Switzerland. This article is an open access article distributed under the terms and conditions of the Creative Commons Attribution (CC BY) license (http://creativecommons.org/licenses/by/4.0/). 